\title{
Critical Appraisal of Amyloid Lowering Agents in AD
}

\author{
Boris Decourt ${ }^{1} \cdot$ Fadel Boumelhem ${ }^{2} \cdot$ Evans D. Pope III $^{1} \cdot$ Jiong Shi ${ }^{1} \cdot$ Zoltan Mari $^{1} \cdot$ Marwan Noel Sabbagh $^{1}$
}

Accepted: 27 May 2021 / Published online: 10 June 2021

(C) The Author(s) 2021

\begin{abstract}
Purpose of Review According to the amyloid cascade hypothesis, removing amyloid beta (A $\beta$ ) should cure Alzheimer's disease (AD). In the past three decades, many agents have been tested to try to lower $A \beta$ production, prevent $A \beta$ aggregation, and dissolve $A \beta$ deposits. However, the paucity in definitive preventative or curative properties of these agents in clinical trials has resulted in more avant-garde approaches to therapeutic investigations. Immunotherapy has become an area of focus for research on disease-modifying therapies for neurodegenerative diseases. In this review, we highlight the current clinical development landscape of monoclonal antibody $(\mathrm{mAb})$ therapies that target $\mathrm{A} \beta$ plaque formation and removal in $\mathrm{AD}$.

Recent Findings Multiple potential disease-modifying therapeutics for AD are in active development. Targeting A $\beta$ with $\mathrm{mAbs}$ has the potential to treat various stages of AD: prodromal, prodromal to mild, mild, and mild to moderate. Monoclonal antibodies discussed here include aducanumab, lecanemab, solanezumab, crenezumab, donanemab, and gantenerumab.

Summary The final decision by the FDA regarding the approval of aducanumab will offer valuable insight into the trajectory of drug development for $\mathrm{mAbs}$ in $\mathrm{AD}$ and other neurodegenerative diseases. Future directions for improving the treatment of $\mathrm{AD}$ will include more inquiry into the efficacy of $\mathrm{mAbs}$ as disease-modifying agents that specifically target $\mathrm{A} \beta$ peptides and/or multimers. In addition, a more robust trial design for $\mathrm{AD}$ immunotherapy agents should improve outcomes such that objective measures of clinical efficacy will eventually lead to higher chances of drug approval.
\end{abstract}

Keywords Alzheimer's disease $\cdot$ Amyloid beta $\cdot$ Immunotherapy $\cdot$ Monoclonal antibody therapy

\section{Introduction}

Alzheimer's disease (AD) is the most prevalent type of dementia, affecting 5.8 million people ages 65 and older in the USA alone, and this number is estimated to grow to 13.8 million by mid-century [1]. In other words, one in ten people ages 65 and older (10\%) have AD in the USA [1]. Following the onset of $\mathrm{AD}$ dementia, the median survival time ranges from 3.3 to 11.7 years. [2]. Because the number of deaths continues to increase, and because of the tremendous financial burden to society, the need for disease-modifying treatments for $\mathrm{AD}$ is dire.

This article is part of the Topical Collection on Dementia

Marwan Noel Sabbagh

sabbagm@ccf.org

1 Cleveland Clinic Lou Ruvo Center for Brain Health, 888 W. Bonneville Ave, Las Vegas, NV 89106, USA

2 UNLV School of Medicine, Las Vegas, NV, USA
The two neuropathological hallmarks of $\mathrm{AD}$ are amyloid $\beta$ $(\mathrm{A} \beta)$ plaques and neurofibrillary tangles (NFT) [3, 4]. NFTs consist of filamentous inclusions or aggregates of aberrantly misfolded and hyperphosphorylated tau proteins that accumulate intra-neuronally [3]. A $\beta$ peptides (molecular weight $\sim 4 \mathrm{kDa}$ ) are the product of the successive cleavage of amyloid precursor protein (APP; molecular weight $\sim 120 \mathrm{kDa}$ ) by $\beta$ - and $\gamma$-secretases, which is referred to as the amyloidogenic pathway [5]. Alternatively, APP can be first cleaved by an $\alpha$-secretase inside the amyloid peptide sequence (i.e., amino acid 16), then $\gamma$ secretase to generates shorter soluble extracellular fragments, termed $\mathrm{p} 3$, that are thought to be non-amyloidogenic [5].

During the course of $A D, A \beta$ peptides that are $36-43$ amino acids long (e.g., $A \beta_{40}, A \beta_{42}, A \beta_{43}$ ) can assemble into insoluble beta-sheet fibrillar aggregates that deposit extracellularly in the brain parenchyma and cerebral vasculature $[6,7]$. Over time, amyloid plaques may grow from a single $A \beta$ fibril extracellular nucleation site [8]. Amyloid deposition is accompanied with the disruption of synaptic structure and function, and neuronal atrophy often starting in the hippocampus area then spreading to cortical regions, which ultimately induces 
cognitive impairment and dementia symptoms [9-11]. Cerebral vasculature deposits (also known as cerebral amyloid angiopathy; CAA) can cause hemorrhages, strokes, and inflammation $[6,7]$. The mechanism of toxicity of amyloid peptides is widely debated. The mechanism can be viewed either as a gain-of-toxicity in the amyloid peptides and their soluble misfolded oligomeric antecedents [12-14], or as a loss of function due to the adoption of misfolded conformations [15]. Some argue that $A \beta$ is intrinsically toxic. Others suggest $A \beta$ seeds the formation of tau tangles $[14,16]$.

According to the amyloid cascade hypothesis, which was introduced in 1992, deposition of $A \beta$ peptides is the main causative agent of AD pathology, i.e., NFT, cell loss, CAA, vascular damage, and dementia follows as a direct result of this deposition [17]. Phenotypic heterogeneity of AD pathology is suggested to be induced by polymorphic $A \beta$ fibrils that precipitate as heterogeneous plaque pathology, such as cored (mature) plaques and diffuse plaques [18-20]. Importantly, based upon the amyloid cascade hypothesis, the removal of brain $\mathrm{A} \beta$ plaques should stop the progression of $\mathrm{AD}$. This concept stimulated the development and testing of highly innovative anti- $\mathrm{A} \beta$ therapeutic agents in the past three decades to lower $A \beta$ production, prevent $A \beta$ aggregation, and dissolve $A \beta$ deposits. However, this idea is currently debated due to the failure of all clinical trials testing this concept until now [32657175].

Diffuse plaques are frequently observed in cognitively unaffected, amyloid positive (CU-AP) individuals [21]. Diffuse plaques have been found to have a capacity to convert into cored plaques in sporadic $\mathrm{AD}$ (s-AD) [21]. Maturation of diffuse into cored plaques in $\mathrm{s}-\mathrm{AD}$ was found to correlate with increased deposition of $A \beta_{40}$ at the center of the cored plaques [21]. Diffuse plaques in both s-AD and CU-AP are characterized by deposition of $A \beta_{42}$ [21]. Moreover, diffuse plaques in s-AD show increased levels of pyroglutamate-modified $N$ terminally truncated $A \beta_{42}$ species (N-pyro-E-A $\beta ; A \beta p E 3-$ $42, A \beta p E 11-42)$ in comparison with diffuse plaques in CU$\mathrm{AP}$ [21]. The correlation of s-AD with deposition of $A \beta_{40}$ and the finding of increased diffuse $A \beta_{42}$ rich plaques in CU-AP patients is contrary to the current understanding that $A \beta_{42}$ is the major $A \beta$ toxic species associated with $A D$ pathogenesis, and suggests a more complex mechanism involving $A \beta_{40}$ as well [21-24].

$A \beta$ peptides vary in toxicity, with $A \beta_{43}$ being the most cytotoxic and $A \beta_{40}$ being the most benign as it is produced physiologically throughout life [5, 25-27]. $\mathrm{A} \beta_{42}$ demonstrates neurotoxicity and has the faster aggregation rate [28]. The most synaptotoxic species of $A \beta$ are the small oligomers (2-10 monomers), and pyroglutamate forms of $A \beta$ oligomers [29]. The current hypothesis is that both soluble and insoluble $\mathrm{A} \beta$ fibrils may contribute to the pathogenesis and progression of $\mathrm{AD}$ [28]. Thus, using $\mathrm{A} \beta$ lowering agents is still considered a viable approach as a disease-modifying treatment for $\mathrm{AD}$.
Below, we review the main $\mathrm{A} \beta$ lowering approaches tested in humans and an accurate update on their clinical testing.

\section{A $\beta$ Synthesis Inhibitors}

Several mechanisms have previously targeted the inhibition of $A \beta$ production, namely through inhibition of $\beta$-site amyloid protein cleaving enzymes 1 and 2 (BACE1 and BACE2), and $\gamma$-secretase. BACE1, which is an enzyme from the aspartyl protease class, is the major $\beta$-secretase in the brain [30].

In transgenic mouse models of $\mathrm{AD}, \mathrm{BACE} 1$ inhibitors dose-dependently lowered $A \beta$ levels in the brain and CSF; however, very few studies have shown the ability to reduce the memory and behavioral deficits in such mouse models [ 30 , 31]. Many BACE1 inhibitors clinical trials showed significantly lowered $A \beta$ levels in the plasma and CSF, and reduced brain amyloid loads but without cognitive, clinical, or functional benefit [30]. A few of these clinical trials were terminated prematurely due to toxicity or cognitive and behavioral worsening compared to placebo-treated patients [30]. Elenbecestat was the last BACE1 inhibitor in phase III clinical trials (NCT02956486) [30]. However, the sponsors, Eisai and Biogen, reported during a press release the discontinuation of the phase III clinical trial due to "unfavorable risk-benefit ratio" [30]. Other BACE1 inhibitors such as LY3202626 (Eli Lilly \& Co) and umibecestat/CNP520 (Novartis Pharmaceuticals Corporation and Amgen, Inc.) were also abandoned due to no clear effects on cognition for LY3202626 and worsened cognition, brain atrophy and weight loss for umibecestat [30]. There are currently no BACE1 inhibitors in active clinical trials [30].

Drugs targeting $\gamma$-secretase also showed unfavorable results in clinical trials. For example, a phase II clinical trial for avagacestat (Bristol-Myers Squibb) given orally showed no evidence of efficacy and was associated with adverse doselimiting effects (predominantly gastrointestinal and dermatologic) $[32,33]$. Many $\gamma$-secretase inhibitors were also associated with significantly increased risk of serious adverse events (SAEs) such as skin cancers and cognitive decline. The high frequency of AEs associated with these drugs is making them less likely to be widespread agents for the pharmacological treatment of $\mathrm{AD}$ [34].

Since $\gamma$-secretase inhibition was unsuccessful, some efforts were getting directed towards $\gamma$-secretase modulators instead, which were expected to be safer as they target the $\gamma$-secretase complex through allosteric binding and modify its enzymatic activity instead of competing for substrates [35]. In preclinical settings, $\gamma$-secretase modulators such as rofecoxib (Merck), tarenflurbil (Myriad Genetics), or naproxen (Procter \& Gamble) were able to reduce levels of $A \beta_{42}$ and produce shorter peptides that are non-amyloidogenic [36-38]. However, $\gamma$-secretase modulators failed to show efficacy in clinical trials, which was explained by the very poor blood- 
brain barrier (BBB) crossing ability of these drugs [38]. Nonetheless, a new generation of $\gamma$-secretase modulators is currently under pre-clinical investigation [33479693].

\section{A $\beta$ Agglomeration Inhibitors}

Agents such as metal chelators, resveratrol, cromolyn sodium, and ibuprofen have been explored as potential agglomeration inhibitors. However, and as detailed below, as the date of writing of this paper, none of these agents have shown any substantial effects on improving cognitive abilities in AD clinical trials.

Deferiprone (Chiesi Pharmaceuticals Inc. and Apotex Inc.) is an iron chelator that is undergoing a phase II clinical trial (NCT03234686). The reasoning behind iron chelation is that $\mathrm{Fe}^{3+}$ is able to bind to $\mathrm{A} \beta_{42}$ via His 6, Asp7, Tyr10, and His14, which all facilitate $A \beta$ aggregation [39 40]. Previously, the metal chelator clioquinol (also called iodochlorhydroxyquin or PBT1; Prana Biotechnology Limited) was being developed. But it was terminated due to a toxic contaminant [39]. The second-generation compound following PBT1, termed PBT2, had improved BBB crossing abilities and pharmacokinetics compared to PBT1. PBT2 reduces extracellular copper and zinc ions by translocating them into the cells and thus reduces metalmediated A $\beta$ aggregation [40-42]. PBT2 underwent two phase II clinical trials. The first one (NCT00471211) showed a decrease in $\mathrm{A} \beta_{42}$ in CSF but no cognitive improvement. The second one (ACTRN12611001008910) showed no difference between the treatment and placebo groups [43].

Resveratrol is a polyphenol found in some more than 70 plant species, most predominantly in grapes' skin and seeds, and even in red wine [44]. The reasoning behind using resveratrol for $\mathrm{AD}$ treatment is that it can inhibit oxidative stress and activate the anti-aging gene SIRT1, which both are associated with decreased $A \beta$ deposition $[45,46]$. For example, $\operatorname{Tg} 19959$ mice treated with resveratrol showed a significant reduction in $A \beta$ plaque formation by up to $90 \%$ [45]. There is currently one active phase I clinical trial for resveratrol that is recruiting patients with mild cognitive impairment, and patients that are pre-diabetic or type II diabetes mellitus (NCT02502253). The reasoning why pre-diabetic and diabetic patients are investigated is because high glucose levels increase the risk of incident cognitive impairment and possibly $\mathrm{AD}[47]$.

ALZT-OP1 (AZTherapies, Inc.) is a combination of cromolyn sodium and ibuprofen that is used in clinical trials to assess effects on $A \beta$ plaque aggregation [48]. There is currently one active phase I/II clinical trial (NCT04570644) for ALZT-OP1 assessing the effects on AD patients and healthy volunteers. Cromolyn sodium is a prescription drug used in the treatment of asthma, and its mechanism of action is inhibition of mast cell degranulation, hence the modulation of inflammatory events [48]. Ibuprofen is a non-steroidal anti- inflammatory drug (NSAID) that inhibits cyclooxygenase (COX) 1 and 2. Although ibuprofen alone had no significant cognitive effect, cromolyn alone or combined with ibuprofen was found to inhibit the deposition of $A \beta$ via the promotion of microglia recruitment and phagocytosis $[48,49]$.

\section{Immunotherapies as $A \beta$ Deposition Inhibitors and Plaques Dissolution Agents}

Since it was reported in 1999 that active immunization against $\mathrm{A} \beta$ reversed amyloid pathology in transgenic mice, academia and industry have worked intensively on the development of passive and active anti-A $\beta$ immunotherapeutics for $\mathrm{AD}[50]$.

Active immunization entails a vaccination approach with the administration of $A \beta$ as the antigen to elicit an immune response against $A \beta$ [51]. Such an approach was first pursued in 2002 by administering pre-aggregated $A \beta_{42}$ along with the immunological adjuvant QS-21 [51]. Although this innovative paradigm significantly reduced $A \beta$ brain deposits in $A D$ patients, it did not produce any cognitive or clinical benefits [51].

Monoclonal anti-A $\beta$ antibodies (mAbs) are passive immunotherapy initiatives that have been investigated thoroughly as a treatment for $\mathrm{AD}$. The current armamentarium of mAbs differs in selectivity for polymorphic variants and may recognize epitopes either based on a specific portion of the $A \beta$ sequence, or one of the multimeric $\mathrm{A} \beta$ conformations [52]. Although up until early 2019 all mAb therapeutics failed in phase III clinical trials, the relative "success" of aducanumab with their phase III study that was reported in December of 2019 rendered some excitement among the AD researchers and patients [53]. Furthermore, the recent reports on donanemab are reinvigorating hope for the use of anti-A $\beta$ $\mathrm{mAbs}$ in the treatment of $\mathrm{AD}$. Below, we describe the major immunotherapies applied to lower brain $A \beta$ levels that are still currently investigated in clinical trials. The current $\mathrm{mABs}$ are summarized in Table 1.

\section{Aducanumab}

Aducanumab (ADU) is currently one of the most promising mAbs approaching approval by the U.S. Food and Drug Administration (FDA). ADU is a recombinant human IgG1 antibody that primarily binds to both soluble and insoluble $A \beta$ amyloid aggregates with $>10,000$-fold selectivity over monomers [52]. It was derived from a blood lymphocyte library collected from a healthy donor population of elderly subjects who were lacking signs of cognitive impairment or with unusually slow cognitive decline [52]. ADU binds to $A \beta$ residues 3-7 in an extended conformation [52]. It is capable of selectively targeting the pathological oligomeric and fibrillar forms of $A \beta$ [52]. 
Table 1 Properties of selected anti-A $\beta$ antibodies currently tested in clinical trials for AD

\begin{tabular}{|c|c|c|c|c|c|}
\hline $\begin{array}{l}\text { mAb clinical } \\
\text { candidate }\end{array}$ & $\begin{array}{l}\text { Mouse antibody } \\
\text { analog }\end{array}$ & $\begin{array}{l}\text { Clinical stage } \\
\text { and status }\end{array}$ & $\begin{array}{l}\text { A } \beta \text { selectivity } \\
\text { (monomer, } \\
\text { aggregate) }\end{array}$ & Epitope (residues) & Sponsor \\
\hline Aducanumab & aducanumab & $\begin{array}{l}\text { Phase III, Enrolling by } \\
\text { invitation }\end{array}$ & $\mathrm{A} \gg>\mathrm{M}$ & $3-7$ & Biogen Inc. \\
\hline $\begin{array}{l}\text { Lecanemab } \\
\text { (BAN2401) }\end{array}$ & $\mathrm{mAb} 158$ & Phase III, recruiting & $\mathrm{A} \gg>\mathrm{M}$ & $1-16$ & $\begin{array}{l}\text { Biogen Inc. and Eisai } \\
\text { Co. }\end{array}$ \\
\hline Solanezumab & M266 & Phase III, recruiting & $M \gg>A$ & $16-26$ & Eli Lilly and Co. \\
\hline $\begin{array}{l}\text { Crenezumab } \\
\text { (MABT5102A) }\end{array}$ & MABT5102A & Phase III, terminated & $\mathrm{A}=\mathrm{M}$ & $13-24$ & Genentech Inc. \\
\hline Donanemab & mE8-IgG2a & Phase II, recruiting & $\mathrm{A}>\mathrm{M}$ & $\begin{array}{l}\text { N-terminal } \\
\text { pyroglutamate }\end{array}$ & Eli Lilly and Co. \\
\hline Gantenerumab & gantenerumab & Phase III, recruiting & $\mathrm{A}>\mathrm{M}$ & $3-11,18-27$ & Hoffman-La Roche Inc. \\
\hline
\end{tabular}

Preclinical studies in $\mathrm{Tg} 2576$ mice have shown reduced A $\beta$ plaque size in a dose-dependent manner in young (9 months old) but not aged (22 months old) animals [54, 55], suggesting this $m A b$ prevents $A \beta$ aggregation more than it helps sorbing existing plaques. To note, however, this reduction in $\mathrm{A} \beta$ plaques was not accompanied by any cognitive or behavioral improvement [55].

A phase Ia clinical trial (NCT01397539) completed in 2016 tested single ascending intravenous doses of aducanumab in 53 $\mathrm{AD}$ patients to evaluate the safety, tolerability, and pharmacokinetics [56]. Low doses of $\leq 30 \mathrm{mg} / \mathrm{kg}$ did not show SAEs [56]. All three patients receiving a $60 \mathrm{mg} / \mathrm{kg}$ ADU developed SAEs consisting of amyloid-related imaging abnormalities (ARIA) [56]. None of the patients discontinued or withdrew from treatment due to SAEs, and all SAEs completely resolved within 815 weeks following the single $60 \mathrm{mg} / \mathrm{kg}$ dose administration, which was the final titration dose [56]. Interestingly, at the 60 $\mathrm{mg} / \mathrm{kg}$ dose, $A \beta_{40}$ and $A \beta_{42}$ levels increased in the plasma for $\sim 3$ weeks, suggesting that high levels of ADU bind to soluble monomeric $A \beta$ in humans [56]. However, after 24 weeks of treatment, there was no significant difference in cognitive abilities compared with placebo as measured by the 13-item Alzheimer's Disease Assessment Scale-Cognitive (ADASCog13) [56], positively demonstrating the absence of toxicity on cognition due to ADU.

Analysis of the phase Ib study, PRIME (NCT01677572) showed a significant reduction in brain $A \beta$ loads in prodromal or mild $\mathrm{AD}$ subjects when monitored via florbetapir positron emission tomography (PET) imaging. The results were doseand time-dependent when observed over one year of monthly intravenous infusions [54]. The PRIME analysis also showed that $\mathrm{ADU}$ injections result in a slowing of clinical decline at 1 year, as measured by Mini-Mental State Examination (MMSE) and Clinical Dementia Rating Scale-Sum of Boxes (CDR-SOB) [54].

ADU recently underwent two large phase III clinical trials dubbed "ENGAGE" (NCT02477800) and "EMERGE" (NCT02484547). Both studies were conducted on individuals showing signs of mild cognitive impairment and mild dementia due to $\mathrm{AD}$. The trials used the CDR-SOB as their primary endpoint measurement [57•]. Unfortunately, both trials were terminated in March 2019 by the sponsor, Biogen, due to interim post hoc analyses showing "futility." The data showed EMERGE trending positive and ENGAGE unlikely to meet its primary endpoints. Later in October 2019, Biogen held a press conference to announce that further analyses suggest the benefits of high-dose $(100 \mathrm{mg} / \mathrm{kg})$ ADU in both trials. This prompted Biogen to formally submit a new request for drug approval to the FDA [57•]. However, Biogen claims have been received with some skepticism. For example, Knopman et al. recommended running another trial using high-dose ADU of at least 78 weeks in duration [58]. This recommendation is suggested since post hoc analyses can be fickle and unreliable, indicating that more information needs to be collected to strengthen the existing data before seeking FDA approval [58].

ADU is currently in the pipeline to be reviewed by the FDA [59]. However, a medical advisory committee convened by the FDA did not recommend approval yet, based upon skepticism of adequacy of existing evidence of efficacy [59]. Currently, Biogen has another phase III trial (NCT04241068), which is recruiting patients who were participating in one of the previous ADU studies at the time of the announcement of early termination of ENGAGE and EMERGE.

\section{Lecanemab}

Lecanemab (BAN2401) is a humanized IgG1 version of the mouse monoclonal antibody mAb158. It selectively binds to large, soluble $A \beta$ protofibrils [60]. Preclinical studies have demonstrated its ability to decrease levels of pathogenic $A \beta$, prevent $A \beta$ deposition, and selectively reduce $A \beta$ protofibrils in the brain and CSF in AD animal models [61, 62].

Based on favorable preclinical findings, as well as phase I (NCT02094729) and II (NCT01230853) clinical trial results 
[60], multiple trials are currently investigating BAN2401 as a potential viable treatment option for AD. For example, ClarityAD (NCT03887455) is a phase III randomized, placebo-controlled, double-blind, parallel-group trial that is actively recruiting participants with mild cognitive impairment due to AD. The aim of the study is to evaluate the efficacy of lecanemab in participants with early Alzheimer's disease (EAD) by determining the superiority of lecanemab compared with placebo on the change in cognition from baseline via the CDR-SOB. In this trial, lecanemab $10 \mathrm{mg} / \mathrm{kg}$ will be administered intravenously once every 2 weeks. The anticipated completion date for ClarityAD is June 2022.

Another actively recruiting trial investigating BAN2401 is the AHEAD3-45 trial (NCT04468659). This study aims to the evaluate efficacy and safety of lecanemab in patients with preclinical $\mathrm{AD}$, such as having a first-degree relative diagnosed with dementia onset before age 75 , possessing at least one apolipoprotein $\mathrm{E} 4$ (APOE4) allele, or elevated amyloid levels in the central nervous system (CNS) demonstrated by previous amyloid PET imaging or CSF measurements. Participants will receive lecanemab 5 $\mathrm{mg} / \mathrm{kg}$, administered as intravenous (IV) infusions every 2 weeks through 8 weeks, then $10 \mathrm{mg} / \mathrm{kg}$ administered as IV infusions every 2 weeks through 96 weeks, and $10 \mathrm{mg} / \mathrm{kg}$ administered as IV infusions every 4 weeks through 216 weeks.

Results from these trials will offer clinical evidence to determine whether lecanemab is a robust anti- $\mathrm{A} \beta$ agent in humans as was observed in murine-based studies. Additional long-term trials such as ClarityAD and AHEAD3-45 are needed to continue the quest for definitive clinical outcome results in individuals with early AD.

\section{Solanezumab}

Solanezumab is a humanized monoclonal antibody that preferentially binds to the mid-region of the $\mathrm{A} \beta$ peptide and reduces brain $A \beta$ burden by altering CNS and plasma $A \beta$ clearance in transgenic mouse models of $\mathrm{AD}[63,64]$. This is achieved by solanezumab sequestering all plasma $A \beta$ and creating an efflux of CNS A $\beta$ into the plasma, thus causing a decrease in CSF A $\beta$ levels [65]. Two previous clinical trials investigating solanezumab have been completed, i.e. Expedition 1 (NCT00905372) and Expedition 2 (NCT00904683), while another two trials were recently terminated, i.e., Expedition 3 (NCT01900665) and ExpeditionPRO (NCT02760602). The primary objective of each study was to slow down cognitive decline in patients with mild dementia due to AD [66]. More specifically, Expedition 3 was terminated due to the failure of solazenumab to significantly reduce cognitive decline in patients with mild AD dementia [67]. Further, ExpeditionPRO was terminated due to insufficient scientific evidence that solanezumab would likely demonstrate a meaningful benefit to participants with prodromal AD.
Resulting from the termination of the Expedition studies, researchers have continued to search for a definitive answer on the efficacy of solanezumab. The only trial currently enrolling participants is the DIAN-TU trial, a phase II/III randomized, double-blind, placebo-controlled study which aims to assess whether IV infusion of solanezumab slows the rate of progression of cognitive impairment and improves diseaserelated biomarkers in individuals with mutations causing dominantly inherited AD (NCT01760005). In this parallel assignment study, solanezumab administered every 4 weeks at escalating doses will be compared with gantenerumab, which is a fully humanized IgG1 that has demonstrated high-affinity binding to cerebral $A \beta$ and to significantly reduce $A \beta$ plaques in both $\mathrm{AD}$ transgenic mouse models [68・•] and after 2 years of treatment in humans [69•]. Efficacy will be measured by the change from baseline in the DIAN-multivariate cognitive endpoint which consists of four measures: Wechsler Memory Scale-Revised Logical Memory Delayed Recall Test, Wechsler Adult Intelligence Sale Digit Symbol Substitution Test (WAIS), International Shopping List Task (ISLT), and MMSE. This DIAN-TU study is expected to enroll 490 participants and is projected to reach completion in July 2022. Building on findings from previous clinical studies, this trial, and future trials will assist in determining tolerability, toxicity, and adequate dosing for solanezumab in the AD population. Additionally, the efficacy of solanezumab will be determined as more studies with improved designs investigate its $A \beta$ lowering abilities.

\section{Crenezumab}

Crenezumab (MABT5102A) is a humanized anti-A $\beta$ monoclonal IgG4 with affinity to multiple $A \beta$ species, especially for pentameric and fibrillary 16-mer assemblies of aggregated $\mathrm{A} \beta[70,71]$. Consequently, crenezumab is able to bind both monomeric and aggregated forms of $A \beta$. Crenezumab also possesses anti-aggregative properties towards $A \beta$, promotes disaggregation, and protects neurons from oligomer-induced cytotoxicity $[70,72]$. Crenezumab was created based on the hypothesis that the human IgG4 constant region would modify Fc effector function and reduce vascular side effects [70].

Preclinical studies in Tg2576 mice showed no inflammatory response following intracerebral injection [72]. A completed phase Ib study (NCT02353598) called GN29632 demonstrated tolerability of $\leq 120 \mathrm{mg} / \mathrm{kg}$ doses administered intravenously every 4 weeks [73]. Although $24 \%$ of participants in GN29632 experienced at least one adverse event (AE), most AEs were mild or moderate [73]. Only $4.9 \%$ (double-blind treatment period) and 9.9\% (combined double-blind treatment and open-label extension periods) showed new ARIA-micro hemorrhages and hemosiderosis (ARIA-H), which was not enough to identify any new prominent safety issues [73]. 
Completed phase II clinical trials of crenezumab in patients with mild-to-moderate AD include ABBY (NCT01343966) and BLAZE (NCT01397578) studies [74, 75]. The primary objective for ABBY was an improvement in ADAS-Cog12 and CDR-SOB scores from baseline to week 73 [74]. The primary objective for BLAZE was a favorable change in $A \beta$ burden from baseline to week 69 as measured by florbetapir PET in the modified intent to treat population [75]. Additionally, secondary outcomes for BLAZE were changes in CSF biomarkers and fluorodeoxyglucose PET from baseline to week 69, and changes in ADAS-Cog 12 and CDR-SOB from baseline to week 73 [75]. Although neither of these two studies met their primary or secondary endpoints, positive post hoc analyses in a subset of patients with very mild $A D$ and treated with high dose validates the idea of testing highdose crenezumab in patients in an early stage of AD [74]. Testing with a higher dose is also supported by a phase Ib study (GN29632) [76].

Two recent phase III studies, i.e., CREAD (NCT02670083) and CREAD2 (NCT03114657), have investigated the efficacy and safety of crenezumab at $60 \mathrm{mg} / \mathrm{kg}$, which is 4 times higher than the previous phase II trials. These studies were discontinued following the interim analysis of CREAD, which showed unlikeliness to meet the primary endpoint of change from baseline to week 105 in the CDR-SOB score [76, 77]. The overall safety profile was similar to that seen in previous trials with no obvious safety signals [76].

There is currently one active phase II clinical trial for crenezumab that is recruiting patients in the preclinical phase of AD that carry the presenilin 1 (PSEN1) E280A autosomal dominant mutation (NCT01998841). This study is scheduled for completion in February 2022.

\section{Donanemab}

The latest and most promising $\mathrm{mAb}$ against $\mathrm{A} \beta$ is donanemab (LY3002813, or N3pG). It is a humanized IgG1 that reduces amyloid plaques in $\mathrm{AD}$ by targeting $\mathrm{A} \beta(\mathrm{p} 3-42)$, which is an $\mathrm{N}$-terminal pyroglutamate $\mathrm{A} \beta$ epitope [78]. Lowe et al. recently investigated donanemab in patients with MCI due to AD. Donanemab demonstrated general safety and tolerability in this double-blind, randomized, placebo-controlled, parallelgroup, single-dose followed by a multiple-dose, doseescalation study [79••]. Patients were assigned to five dosing cohorts, ranging from 0.1 to $10 \mathrm{mg} / \mathrm{kg}$, or a placebo cohort followed by a 12 -week follow-up period for each dose. Interestingly, amyloid PET showed that the $10-\mathrm{mg} / \mathrm{kg}$ dose led to brain amyloid load reduction of 40-50\% [79••].

Recent results from the TRAILBLAZER-ALZ trial highlighted donanemab as a promising $\mathrm{mAb}$ treatment of early symptomatic $\mathrm{AD}[80]$. In this multicenter, randomized, double-blinded, placebo-controlled phase II trial, Mintun et al. assessed whether donanemab administration would improve cognition in patients with prodromal or mild AD. For up to 72 weeks, patients were intravenously administered either $700 \mathrm{mg}$ donanemab $(\sim 10 \mathrm{mg} / \mathrm{kg})$ or placebo for the first three doses and $1400 \mathrm{mg}(\sim 20 \mathrm{mg} / \mathrm{kg})$ thereafter every 4 weeks. The primary outcome of TRAILBLAZER-ALZ was the change from baseline on the iADRS at 76 weeks. Secondary outcomes included change in scores on the CDRSB, ADAS-Cog13, MMSE, and Alzheimer's Disease Cooperative Study - Instrumental Activities of Daily Living (ADCS-iADL), along with changes in amyloid and tau levels. At 76 weeks, the donanemab group demonstrated significant improvement on the Integrated Alzheimer's Disease Rating Scale (iADRS) over the placebo group. While donanemab did not lead to improvement in most secondary outcomes, florbetapir and tau PET scans illustrated significant decreases in brain amyloid and tau loads, respectively. These results show the ability of donanemab to positively affect the cognitive and functional decline in early symptomatic $\mathrm{AD}$, which could be applied to other stages of AD.

As a follow-up to the TRAILBLAZER-ALZ study, Eli Lilly and company are currently recruiting participants for a phase II, randomized, parallel assignment study investigating intravenous donanemab in early symptomatic AD (NCT04437511). The primary outcome measure of the TRAILBLAZER-ALZ2 study is the change from baseline on the CDR-SOB. An important inclusion criterion is a gradual and progressive change in memory function reported by participants or informants for $\geq 6$ months. The trial is estimated to reach completion in 2024. It is our opinion that research efforts should place additional focus on donanemab, since it is showing the highest potential as an $\mathrm{A} \beta$-lowering agent accompanied by cognitive improvement among all immunotherapies investigated to date. Future trials will ultimately determine the efficacy of this novel $\mathrm{mAb}$ in the $\mathrm{AD}$ population.

\section{Gantenerumab}

Gantenerumab is a human IgG1 antibody that binds to aggregated $A \beta$ in the brain and lowers amyloid- $\beta$ by eliciting effector cell-mediated clearance [81]. Klein et al. recently reported that gantenerumab doses up to $1200 \mathrm{mg}$ administered subcutaneously once every 4 weeks demonstrated significant $\mathrm{A} \beta$ removal in patients with prodromal to moderate $\mathrm{AD}\left[69^{\circ}\right.$ ]. The main endpoint of this open-label study was the change in the $\mathrm{A} \beta$ plaque burden from baseline to week 52 and week 104. Florbetapir PET was used to assess the efficacy of gantenerumab in $\mathrm{A} \beta$ plaque reduction. Earlier this year, Klein et al. reported that subcutaneous gantenerumab doses up to $1200 \mathrm{mg}$ continued to reduce $\mathrm{A} \beta$ plaque burden at 36 months following treatment initiation $[68 \bullet \bullet$.

In addition to the DIAN-TU phase II trial (NCT01760005), gantenerumab is being investigated in a phase II, multicenter, open-label, single-arm, pharmacodynamic study in 
participants with early AD (NCT04592341). The study is currently recruiting and is planned to be completed in February 2024. Its primary outcome measure is the change from baseline to week 104 in brain amyloid as measured by brain amyloid PET centiloid levels. Enrolled patients will initially be administered a single subcutaneous injection of gantenerumab $120 \mathrm{mg}$ once every 4 weeks for 12 weeks, followed by $255 \mathrm{mg}$ every 4 weeks for 12 weeks, and $255 \mathrm{mg}$ every 2 weeks for another 12 weeks, followed by $255 \mathrm{mg}$ once every week for up to week 103.

A randomized, double-blind, placebo-controlled, parallelgroup phase III study is currently recruiting participants for a study investigating gantenerumab in early AD (NCT03444870). The study will evaluate the efficacy and safety of gantenerumab versus placebo in participants with early $\mathrm{AD}$ and is planned to be completed in November 2023. The primary outcome measure is the change from baseline to week 116 in CDR-SOB score. Trial eligibility includes a diagnosis of probable $\mathrm{AD}$ dementia or prodromal $\mathrm{AD}$, evidence of the $\mathrm{AD}$ pathological process as confirmed by CSF tau $\mathrm{A} \beta_{42}$ or amyloid PET scan, and demonstrated abnormal memory function. Findings from this study combined with results from previous studies will determine future investigations of gantenerumab in the prevention and treatment of $\mathrm{AD}$.

\section{Conclusion}

Highly specific mAbs targeting $A \beta$ are positioned to lead a new generation of disease-modifying therapies for $\mathrm{AD}$. We have assessed the current $\mathrm{mAb}$ drug development landscape, which continues to offer additional therapeutic options. If the FDA approves aducanumab, this would mark a turning point in the drug development landscape since no drug has been approved for the treatment of AD since 2003. Data from aducanumab studies of EMERGE and ENGAGE makes consideration of approval feasible. First, aducanumab resulted in a significant $22 \%$ slowing of decline on the CDR-sb Second, other measures including the Mini-Mental State Examination, Alzheimer's Disease Assessment Scale -cognitive subscale, and mild cognitive impairment (MCI) version of the Alzheimer's Disease Cooperative Study Activities of Daily Living scale (ADCS ADL) demonstrated statistically significant drug-placebo differences in favor of active therapy. Third, care partners reported $84 \%$ less associated distress at week 78 compared to care partners of those on placebo. Finally, in ENGAGE AND EMERGE, participants who received the highest dose of aducanumab for 14 months showed similar levels of slowing on the CDR-sb (30\% slowing in EMERGE, 27\% slowing in ENGAGE).

While approval would offer a much-anticipated treatment option to millions of patients, rejection by the FDA would leave a void in the toolkit of physicians who desperately desire additional options to offer their patients, and a tremendous level of uncertainty in $\mathrm{AD}$ patients and their caregivers. Limited positive outcomes in trials due to the small number of studies investigating other mAbs in AD such as lecanemab, solanezumab, crenezumab, donanemab, and ganterenumab should be further investigated in additional studies.

Each of the mAbs we discussed here has proven to be relatively safe in humans. Results from the phase III trials of ClarityAD, CREAD, and CREAD2 will offer details on the efficacy of their respective drug in improving cognitive and functional impairment as well as imaging indicators of amyloid presence, thus contributing to the growing evidence surrounding $\mathrm{mAb}$ viability in treating neurodegeneration. Future directions should focus on bidirectional studies that may ascertain mechanisms by which immunotherapy leads to improvements in $\mathrm{AD}$.

Conflicts of Interest Dr. Sabbagh discloses the following relationships: Consulting: Alzheon, Biogen, Cortexyme, Roche-Genentech, Stage 2 Innovations/Renew Research, Acadia, T3D, Eisai, KeifeRx. The other authors declare that they have no conflict of interest.

Code Availability Not applicable

Author Contributions $\mathrm{BD}$ and MNS conceived and designed the analysis and finalized the manuscript; FB and EDP collected the data and drafted the article; JS and ZM provided critical revisions of the manuscript. The authors read and approved the final manuscript.

Funding The authors have received funding from the National Institute on Aging (P20GM109025, P20AG068053, R01AG059008, and K01AG047279) and the Keep Memory Alive Foundation.

Data Availability Not applicable

Declarations Not applicable

Ethics Approval and Consent to Participate Not applicable

Consent to Participate This article does not contain any studies with human or animal subjects performed by any of the authors.

Consent for Publication All authors have read the final version of the manuscript and approve its content for publication.

Open Access This article is licensed under a Creative Commons Attribution 4.0 International License, which permits use, sharing, adaptation, distribution and reproduction in any medium or format, as long as you give appropriate credit to the original author(s) and the source, provide a link to the Creative Commons licence, and indicate if changes were made. The images or other third party material in this article are included in the article's Creative Commons licence, unless indicated otherwise in a credit line to the material. If material is not included in the article's Creative Commons licence and your intended use is not permitted by statutory regulation or exceeds the permitted use, you will need to obtain permission directly from the copyright holder. To view a copy of this licence, visit http://creativecommons.org/licenses/by/4.0/. 


\section{References}

Papers of particular interest, published recently, have been highlighted as:

- Of importance

- Of major importance

1. 2020 Alzheimer's disease facts and figures. Alzheimer's Dement. John Wiley and Sons Inc.; 2020;16:391-460; https://doi.org/10. 1002/alz. 12068

2. Todd S, Barr S, Roberts M, Passmore AP. Survival in dementia and predictors of mortality: a review. Int J Geriatr Psychiatry. 2013;28: 1109-24. https://doi.org/10.1002/gps.3946.

3. Serrano-Pozo A, Frosch MP, Masliah E, Hyman BT. Neuropathological alterations in Alzheimer disease. Cold Spring Harb Perspect Med. Cold Spring Harb Perspect Med; 2011;1: a006189-a006189; https://doi.org/10.1101/cshperspect.a006189

4. Bloom GS. Amyloid- $\beta$ and tau: the trigger and bullet in Alzheimer disease pathogenesis. JAMA Neurol [Internet]. American Med Assoc. 2014;71:505-8. https://doi.org/10.1001/jamaneurol.2013. 5847.

5. Benilova I, Karran E, De Strooper B. The toxic A $\beta$ oligomer and Alzheimer's disease: an emperor in need of clothes. Nat Neurosci Nat Pub Group. 2012;15:349-57. https://doi.org/10.1038/nn.3028.

6. Fowler DM, Koulov AV, Alory-Jost C, Marks MS, Balch WE, Kelly JW. Functional amyloid formation within mammalian tissue. In: Weissman J, editor. PLoS Biol, vol. 4: Public Library of Science; 2006. p. 0100-7. https://doi.org/10.1371/journal.pbio. 0040006.

7. Love S, Miners S, Palmer J, Chalmers K, Kehoe P. Insights into the pathogenesis and pathogenicity of cerebral amyloid angiopathy. Front Biosci. (Landmark Ed). 2009;14:4778-92. https://doi.org/ $10.2741 / 3567$

8. Lu J-X, Qiang W, Yau W-M, Schwieters CD, Meredith SC, Tycko R. Molecular structure of $\beta$-amyloid fibrils in Alzheimer's disease brain tissue. Cell. 2013;154:1257-68. https://doi.org/10.1016/j.cell. 2013.08.035.

9. Thal DR, Rüb U, Orantes M, Braak H. Phases of A $\beta$-deposition in the human brain and its relevance for the development of $\mathrm{AD}$. Neurology Lippincott Williams and Wilkins. 2002;58:1791-800. https://doi.org/10.1212/WNL.58.12.1791.

10. Khan UA, Liu L, Provenzano FA, Berman DE, Profaci CP, Sloan $\mathrm{R}$, et al. Molecular drivers and cortical spread of lateral entorhinal cortex dysfunction in preclinical Alzheimer's disease. Nat Neurosci Nature Publishing Group. 2014;17:304-11. https://doi.org/10. 1038/nn.3606.

11. Braak H, Braak E. Neuropathological stageing of Alzheimerrelated changes. Acta Neuropathol Springer-Verlag. 1991;82: 239-59. https://doi.org/10.1007/BF00308809.

12. Olzscha H, Schermann SM, Woerner AC, Pinkert S, Hecht MH, Tartaglia GG, et al. Amyloid-like aggregates sequester numerous metastable proteins with essential cellular functions. Cell Elsevier. 2011;144:67-78. https://doi.org/10.1016/j.cell.2010.11.050.

13. Kayed R, Head E, Thompson JL, McIntire TM, Milton SC, Cotman $\mathrm{CW}$, et al. Common structure of soluble amyloid oligomers implies common mechanism of pathogenesis. Science (80- ). American Association for the Advancement of Science. 2003;300:486-9. https://doi.org/10.1126/science.1079469.

14. Guo JL, Lee VMY. Cell-to-cell transmission of pathogenic proteins in neurodegenerative diseases. Nat Med Nature Publishing Group. 2014;20:130-8. https://doi.org/10.1038/nm.3457.

15. Chuang E, Hori AM, Hesketh CD, Shorter J. Amyloid assembly and disassembly. J Cell Sci Company of Biologists Ltd. 2018;131: 189928. https://doi.org/10.1242/jcs.189928.
16. He Z, Guo JL, McBride JD, Narasimhan S, Kim H, Changolkar L, et al. Amyloid- $\beta$ plaques enhance Alzheimer's brain tau-seeded pathologies by facilitating neuritic plaque tau aggregation. Nat Med Nature Publishing Group. 2018;24:29-38. https://doi.org/10. 1038/nm.4443.

17. Hardy JA, Higgins GA. Alzheimer's disease: the amyloid Alzheimer's disease. Science (80- ). American Association for the Advancement of Science. 1992;256:184-5. https://doi.org/10. 1126/science. 1566067.

18. Dickson TC, Vickers JC. The morphological phenotype of $\beta$ amyloid plaques and associated neuritic changes in Alzheimer's disease. Neurosci Pergamon. 2001;105:99-107. https://doi.org/10. 1016/S0306-4522(01)00169-5.

19. Thal DR, Capetillo-Zarate E, Del Tredici K, Braak H. The development of amyloid beta protein deposits in the aged brain. Sci Aging Knowledge Environ AAAS. 2006. p. re1. https://doi.org/ 10.1126/sageke.2006.6.re1.

20. Ikeda S, Allsop D, Glenner GG. Morphology and distribution of plaque and related deposits in the brains of Alzheimer's disease and control cases. An immunohistochemical study using amyloid $\beta$ protein antibody. Lab Investig. 1989;60:113-22.

21. Michno W, Nyström S, Wehrli P, Lashley T, Brinkmalm G, Guerard L, et al. Pyroglutamation of amyloid- $\beta \mathrm{x}-42(\mathrm{~A} \beta \mathrm{x}-42)$ followed by $\mathrm{A} \beta 1-40$ deposition underlies plaque polymorphism in progressing Alzheimer's disease pathology. J Biol Chem. 2019;294:6719-32. https://doi.org/10.1074/jbc.RA118.006604.

22. Strozyk D, Blennow K, White LR, Launer LJ. CSF Aß 42 levels correlate with amyloid-neuropathology in a population-based autopsy study. Neurology Lippincott Williams and Wilkins. 2003;60: 652-6. https://doi.org/10.1212/01.WNL.0000046581.81650.D0.

23. Fagan AM, Mintun MA, Mach RH, Lee SY, Dence CS, Shah AR, et al. Inverse relation between in vivo amyloid imaging load and cerebrospinal fluid Abeta;42 in humans. Ann Neurol. 2006;59: 512-9. https://doi.org/10.1002/ana.20730.

24. Blennow K, Hampel H, Weiner M, Zetterberg H. Cerebrospinal fluid and plasma biomarkers in Alzheimer disease. Nat Rev Neurol. 2010;6:131-44. https://doi.org/10.1038/nrneurol.2010.4.

25. Burnouf S, Gorsky MK, Dols J, Grönke S, Partridge L. A $\beta 43$ is neurotoxic and primes aggregation of $A \beta 40$ in vivo. Acta Neuropathol Springer Verlag. 2015;130:35-47. https://doi.org/10. 1007/s00401-015-1419-y.

26. Saito T, Suemoto T, Brouwers N, Sleegers K, Funamoto S, Mihira $\mathrm{N}$, et al. Potent amyloidogenicity and pathogenicity of $A \beta 243$. Nat Neurosci Nature Publishing Group. 2011;14:1023-32. https://doi. org/10.1038/nn.2858.

27. Seither KM, McMahon HA, Singh N, Wang H, Cushman-Nick M, Montalvo GL, et al. Specific aromatic foldamers potently inhibit spontaneous and seeded $A \beta 42$ and $A \beta 43$ fibril assembly. Biochem J Portland Press Ltd. 2014;464:85-98. https://doi.org/10.1042/ BJ20131609.

28. Polanco JC, Li C, Bodea LG, Martinez-Marmol R, Meunier FA, Götz J. Amyloid- $\beta$ and tau complexity - towards improved biomarkers and targeted therapies. Nat Rev Neurol Nature Publishing Group. 2018;14:22-40. https://doi.org/10.1038/nrneurol.2017.162.

29. Thal DR, Walter J, Saido TC, Fändrich M. Neuropathology and biochemistry of $A \beta$ and its aggregates in Alzheimer's disease. Acta Neuropathol. Springer Verlag; 2015. p. 167-182; https://doi. org/10.1007/s00401-014-1375-y

30. Imbimbo BP, Watling M. Investigational BACE inhibitors for the treatment of Alzheimer's disease. Expert Opin Investig Drugs Taylor Francis Ltd. 2019;28:967-75. https://doi.org/10.1080/ 13543784.2019.1683160.

31. Coimbra JRM, Marques DFF, Baptista SJ, Pereira CMF, Moreira PI, Dinis TCP, et al. Highlights in BACE1 inhibitors for Alzheimer's disease treatment. Front Chem. Frontiers Media S A. 2018;6:1-10. https://doi.org/10.3389/fchem.2018.00178. 
32. Coric V, van Dyck CH, Salloway S, Andreasen N, Brody M, Richter RW, et al. Safety and tolerability of the $\gamma$-secretase inhibitor Avagacestat in a phase 2 study of mild to moderate Alzheimer disease. Arch Neurol. 2012;69:1430-40. https://doi.org/10.1001/ archneurol.2012.2194.

33. Coric V, Salloway S, Van Dyck CH, Dubois B, Andreasen N, Brody $\mathrm{M}$, et al. Targeting prodromal Alzheimer disease with avagacestat: a randomized clinical trial. JAMA Neurol American Medical Association. 2015;72:1324-33. https://doi.org/10.1001/ jamaneurol.2015.0607.

34. Penninkilampi R, Brothers HM, Eslick GD. Pharmacological agents targeting $\gamma$-secretase increase risk of cancer and cognitive decline in Alzheimer's disease patients: a systematic review and meta-analysis. J Alzheimers Dis. IOS Press. 2016;53:1395-404. https://doi.org/10.3233/JAD-160275.

35. Bursavich MG, Harrison BA, Blain JF. Gamma secretase modulators: new Alzheimer's drugs on the horizon? J Med Chem American Chemical Society. 2016;59:7389-409. https://doi.org/ 10.1021/acs.jmedchem.5b01960.

36. Reines SA, Block GA, Morris JC, Liu G, Nessly ML, Lines CR, et al. No effect on Alzheimer's disease in a 1-year, randomized, blinded, controlled study. Neurology Lippincott Williams and Wilkins. 2004;62:66-71. https://doi.org/10.1212/WNL.62.1.66.

37. Green RC, Schneider LS, Amato DA, Beelen AP, Wilcock G, Swabb EA, et al. Effect of tarenflurbil on cognitive decline and activities of daily living in patients with mild Alzheimer disease: a randomized controlled trial. JAMA - J Am Med Assoc. American Medical Association. 2009;302:2557-64. https://doi.org/10.1001/ jama.2009.1866.

38. Meyer P-F, Tremblay-Mercier J, Leoutsakos J, Madjar C, LafailleMaignan M-É, Savard M, Rosa-Neto P, Poirier J, Etienne P, Breitner J, for the PREVENT-AD research group INTREPAD: a randomized trial of naproxen to slow progress of presymptomatic Alzheimer disease. Neurology. Lippincott Williams and Wilkins; 2019;92:e2070-2080; https://doi.org/10.1212/WNL. 0000000000007232

39. Sampson EL, Jenagaratnam L, McShane R. Metal protein attenuating compounds for the treatment of Alzheimer's dementia. Cochrane Database Syst Rev John Wiley and Sons Ltd. 2014;2014:CD005380. https://doi.org/10.1002/14651858. CD005380.pub5.

40. Bush AI, Tanzi RE. Therapeutics for Alzheimer's disease based on the metal hypothesis. Neurotherapeutics. 2008;5:421-32. https:// doi.org/10.1016/j.nurt.2008.05.001.

41. Crouch PJ, Savva MS, Hung LW, Donnelly PS, Mot AI, Parker SJ, et al. The Alzheimer's therapeutic PBT2 promotes amyloid- $\beta$ degradation and GSK3 phosphorylation via a metal chaperone activity. J Neurochem. 2011;119:220-30. https://doi.org/10.1111/j.14714159.2011.07402.x.

42. Adlard PA, Bica L, White AR, Nurjono M, Filiz G, Crouch PJ, Donnelly PS, Cappai R, Finkelstein DI, Bush AI Metal ionophore treatment restores dendritic spine density and synaptic protein levels in a mouse model of Alzheimer's disease. PLoS One PLoS One; 2011;6:e17669; https://doi.org/10.1371/journal.pone. 0017669

43. Lannfelt L, Blennow K, Zetterberg H, Batsman S, Ames D, Harrison J, et al. Safety, efficacy, and biomarker findings of PBT2 in targeting A $\beta$ as a modifying therapy for Alzheimer's disease: a phase IIa, double-blind, randomised, placebo-controlled trial. Lancet Neurol Lancet Publishing Group. 2008;7:779-86. https://doi.org/10.1016/S1474-4422(08)70167-4.

44. Salehi B, Mishra A, Nigam M, Sener B, Kilic M, Sharifi-Rad M, et al. Resveratrol: a double-edged sword in health benefits. Biomedicines. MDPI AG. 2018;6:91. https://doi.org/10.3390/ biomedicines6030091.
45. Karuppagounder SS, Pinto JT, Xu H, Chen HL, Beal MF, Gibson GE. Dietary supplementation with resveratrol reduces plaque pathology in a transgenic model of Alzheimer's disease. Neurochem Int Pergamon. 2009;54:111-8. https://doi.org/10.1016/j.neuint. 2008.10.008.

46. Karuppagounder SS, Pinto JT, Xu H, Chen HL, Beal MF, Gibson GE. Dietary supplementation with resveratrol reduces plaque pathology in a transgenic model of Alzheimer's disease. Neurochem Int Pergamon. 2009;54:111-8. https://doi.org/10.1016/j.neuint. 2008.10.008.

47. Zilliox LA, Chadrasekaran K, Kwan JY, Russell JW. Diabetes and cognitive impairment. Curr Diab Rep Current Medicine Group LLC 1. 2016;16:87. https://doi.org/10.1007/s11892-016-0775-x.

48. Zhang C, Griciuc A, Hudry E, Wan Y, Quinti L, Ward J, et al. Cromolyn reduces levels of the Alzheimer's disease-associated amyloid $\beta$-protein by promoting microglial phagocytosis. Sci Rep Nature Publishing Group. 2018;8:1144. https://doi.org/10.1038/ s41598-018-19641-2.

49. Jaturapatporn D, Isaac MGEKN, McCleery J, Tabet N. Aspirin, steroidal and non-steroidal anti-inflammatory drugs for the treatment of Alzheimer's disease. Cochrane Database Syst Rev Wiley. 2012:CD006378. https://doi.org/10.1002/14651858.CD006378. pub2.

50. Schenk D, Barbour R, Dunn W, Gordon G, Grajeda H, Guldo T, et al. Immunization with amyloid- $\beta$ attenuates Alzheimer diseaselike pathology in the PDAPP mouse. Nature Nature Publishing Group. 1999;400:173-7. https://doi.org/10.1038/22124.

51. Holmes C, Boche D, Wilkinson D, Yadegarfar G, Hopkins V, Bayer A, et al. Long-term effects of A $\beta 42$ immunisation in Alzheimer's disease: follow-up of a randomised, placebocontrolled phase I trial. Lancet Elsevier. 2008;372:216-23. https:// doi.org/10.1016/S0140-6736(08)61075-2.

52. Arndt JW, Qian F, Smith BA, Quan C, Kilambi KP, Bush MW, et al. Structural and kinetic basis for the selectivity of aducanumab for aggregated forms of amyloid- $\beta$. Sci Rep. 2018;8:1-16. https:// doi.org/10.1038/s41598-018-24501-0.

53. Panza F, Lozupone M, Logroscino G, Imbimbo BP. A critical appraisal of amyloid- $\beta$-targeting therapies for Alzheimer disease. Nat Rev Neurol Springer US. 2019;15:73-88. https://doi.org/10.1038/ s41582-018-0116-6.

54. Sevigny J, Chiao P, Bussière T, Weinreb PH, Williams L, Maier M, et al. The antibody aducanumab reduces A $\beta$ plaques in Alzheimer's disease. Nature Nature Publishing Group. 2016;537:50-6. https:// doi.org/10.1038/nature19323.

55. Kastanenka KV, Bussiere T, Shakerdge N, Qian F, Weinreb PH, Rhodes K, et al. Immunotherapy with aducanumab restores calcium homeostasis in Tg2576 mice. J Neurosci Society for Neuroscience. 2016;36:12549-58. https://doi.org/10.1523/JNEUROSCI.2080-16. 2016.

56. Ferrero J, Williams L, Stella H, Leitermann K, Mikulskis A, O'Gorman J, et al. First-in-human, double-blind, placebo-controlled, single-dose escalation study of aducanumab (BIIB037) in mild-to-moderate Alzheimer's disease. Alzheimer's Dement Transl Res Clin Interv Elsevier Inc. 2016;2:169-76. https://doi.org/10. 1016/j.trci.2016.06.002.

57. Haeberlein SB, von Hehn C, Tian Y, Chalkias S, Muralidharan $\mathrm{KK}$, Chen T, et al. Emerge and engage topline results: phase 3 studies of aducanumab in early Alzheimer's disease. Alzheimers Dement. Wiley; 2020;16; https://doi.org/10.1002/alz.047259. Results from EMERGE and ENGAGE offered conflicting data that has led some researchers to question and oppose the potential FDA approval aducanumab for treatment of AD.

58. Knopman DS, Jones DT, Greicius MD. Failure to demonstrate efficacy of aducanumab: An analysis of the EMERGE and ENGAGE trials as reported by Biogen. Alzheimers Dement. 2019;2020:1-6. https://doi.org/10.1002/alz.12213. 
59. Fillit $\mathrm{H}$, Green A. Aducanumab and the FDA — where are we now? Nat Rev Neurol Springer US. 2021;17:129-30. https://doi.org/10. 1038/s41582-020-00454-9.

60. Logovinsky V, Satlin A, Lai R, Swanson C, Kaplow J, Osswald G, et al. Safety and tolerability of BAN2401 - a clinical study in Alzheimer's disease with a protofibril selective $A \beta$ antibody. Alzheimers Res Ther BioMed Central Ltd.; 2016;8; https://doi. org/10.1186/s13195-016-0181-2

61. Tucker S, Möller C, Tegerstedt K, Lord A, Laudon H, Sjödahl J, et al. The murine version of BAN2401 (mAb158) selectively reduces amyloid- $\beta$ protofibrils in brain and cerebrospinal fluid of tgArcSwe Mice. J Alzheimers Dis IOS Press. 2015;43:575-88. https://doi.org/10.3233/JAD-140741.

62. Söllvander S, Nikitidou E, Gallasch L, Zyśk M, Söderberg L, Sehlin $\mathrm{D}$, et al. The $\mathrm{A} \beta$ protofibril selective antibody mAb158 prevents accumulation of $A \beta$ in astrocytes and rescues neurons from $A \beta$-induced cell death. J Neuroinflammation. BioMed Central Ltd.; 2018;15; https://doi.org/10.1186/s12974-018-1134-4

63. Legleiter J, Czilli DL, Gitter B, DeMattos RB, Holtzman DM, Kowalewski T. Effect of different anti-Abeta antibodies on Abeta fibrillogenesis as assessed by atomic force microscopy. J Mol Biol. 2004;335:997-1006. https://doi.org/10.1016/j.jmb.2003.11.019.

64. DeMattos RB, Bales KR, Cummins DJ, Dodart JC, Paul SM, Holtzman DM. Peripheral anti-A beta antibody alters CNS and plasma A beta clearance and decreases brain A beta burden in a mouse model of Alzheimer's disease. Proc Natl Acad Sci U S A. 2001;98:8850-5. https://doi.org/10.1073/pnas.151261398.

65. DeMattos RB, Bales KR, Cummins DJ, Paul SM, Holtzman DM. Brain to plasma amyloid-beta efflux: a measure of brain amyloid burden in a mouse model of Alzheimer's disease. Science. 2002;295:2264-7. https://doi.org/10.1126/science.1067568.

66. Doody RS, Thomas RG, Farlow M, Iwatsubo T, Vellas B, Joffe S, et al. Phase 3 trials of solanezumab for mild-to-moderate Alzheimer's disease. N Engl J Med. 2014;370:311-21. https://doi. org/10.1056/nejmoa1312889.

67. Honig LS, Vellas B, Woodward M, Boada M, Bullock R, Borrie M, et al. Trial of solanezumab for mild dementia due to Alzheimer's disease. N Engl J Med. 2018;378:321-30. https://doi.org/10.1056/ nejmoa1705971.

68.• Klein G, Delmar P, Kerchner GA, Hofmann C, Abi-Saab D, Davis A, et al. Thirty-six-month amyloid positron emission tomography results show continued reduction in amyloid burden with subcutaneous gantenerumab. J Prev Alzheimer's Dis. 2021;8:3-6. https:// doi.org/10.14283/jpad.2020.68 This study demonstrates potential long-term efficacy of gantenerumab as an amyloid lowering $\mathbf{m A b}$ in AD.

69. Klein G, Delmar P, Voyle N, Rehal S, Hofmann C, Abi-Saab D, et al. Gantenerumab reduces amyloid- $\beta$ plaques in patients with prodromal to moderate Alzheimer's disease: a PET substudy interim analysis. Alzheimers Res Ther. 2019;11:101; https://doi.org/10. 1186/s13195-019-0559-z. Based on these results, gantenerumab was established as a safe and effective potential AD treatment.

70. Adolfsson O, Pihlgren M, Toni N, Varisco Y, Buccarello AL, Antoniello K, et al. An effector-reduced anti- $\beta$-amyloid $(A \beta)$ antibody with unique $A \beta$ binding properties promotes neuroprotection and glial engulfment of A $\beta$. J Neurosci Society for Neuroscience. 2012;32:9677-89. https://doi.org/10.1523/JNEUROSCI.4742-11. 2012.

71. Zhao J, Nussinov R, Ma B. Mechanisms of recognition of amyloid$\beta(A \beta)$ monomer, oligomer, and fibril by homologous antibodies. J
Biol Chem American Society for Biochemistry and Molecular Biology Inc.; 2017;292:18325-43; https://doi.org/10.1074/jbc. M117.801514

72. Ultsch M, Li B, Maurer T, Mathieu M, Adolfsson O, Muhs A, et al. Structure of crenezumab complex with a $\beta$ shows loss of $\beta$-hairpin. Sci Rep Nature Publishing Group. 2016;6:1-11. https://doi.org/10. 1038/srep39374.

73. Guthrie H, Honig LS, Lin H, Sink KM, Blondeau K, Quartino A, et al. Safety, tolerability, and pharmacokinetics of crenezumab in patients with mild-to-moderate Alzheimer's disease treated with escalating doses for up to 133 weeks. J Alzheimers Dis. 2020;76: 967-79. https://doi.org/10.3233/JAD-200134.

74. Cummings JL, Cohen S, Van Dyck CH, Brody M, Curtis C, Cho $\mathrm{W}$, et al. A phase 2 randomized trial of crenezumab in mild to moderate Alzheimer disease. Neurology. 2018;90:E1889-97. https://doi.org/10.1212/WNL.0000000000005550.

75. Salloway S, Honigberg LA, Cho W, Ward M, Friesenhahn M, Brunstein $\mathrm{F}$, et al. Amyloid positron emission tomography and cerebrospinal fluid results from a crenezumab anti-amyloid-beta antibody double-blind, placebo-controlled, randomized phase II study in mild-to-moderate Alzheimer's disease (BLAZE). Alzheimers Res Ther Alzheimer's Research \& Therapy;. 2018;10: 1-13. https://doi.org/10.1186/s13195-018-0424-5.

76. Yoshida K, Moein A, Bittner T, Ostrowitzki S, Lin H, Honigberg L, et al. Pharmacokinetics and pharmacodynamic effect of crenezumab on plasma and cerebrospinal fluid beta-amyloid in patients with mild-to-moderate Alzheimer's disease. Alzheimers Res Ther. 2020;12:1-12. https://doi.org/10.1186/s13195-020-0580-2.

77. Bittner T, Duning T, Rabe C, Clayton D, Quartino A, Bohorquez SS, et al. P32 Phase III studies of crenezumab in early (prodromalto-mild) Alzheimers disease (CREAD/CREAD2): biomarker results. Clin Neurophysiol Elsevier BV. 2020;131:e194-5. https:// doi.org/10.1016/j.clinph.2019.12.038.

78. Irizarry MC, Sims JR, Lowe SL, Nakano M, Hawdon A, Willis BA, et al. O4-08-06: Safety, pharmacokinetics (PK), and florbetapir F-18 positron emission tomography (PET) after multiple dose administration of LY3002813, A $\beta$-amyloid plaque-specific antibody, IN Alzheimer's disease (AD). Alzheimers Dement Wiley. 2016;12: P352-3. https://doi.org/10.1016/j.jalz.2016.06.665.

79.• Lowe SL, Willis BA, Hawdon A, Natanegara F, Chua L, Foster J, et al. Donanemab (LY3002813) dose-escalation study in Alzheimer's disease. Alzheimer's Dement (New York, N Y). 2021\;7 https://doi.org/10.1002/trc2.12112. Donanemab improved iADRS score and reduced both amyloid plaque level and global tau load in participants with early symptomatic AD.

80. Mintun MA, Lo AC, Duggan Evans C, Wessels AM, Ardayfio PA, Andersen SW, et al. Donanemab in early Alzheimer's disease. N Engl J Med. 2021;384:1691-704. https://doi.org/10.1056/ NEJMoa2100708.

81. Bohrmann B, Baumann K, Benz J, Gerber F, Huber W, Knoflach F, et al. Gantenerumab: a novel human anti-A $\beta$ antibody demonstrates sustained cerebral amyloid- $\beta$ binding and elicits cellmediated removal of human amyloid- $\beta$. J Alzheimers Dis. 2012;28:49-69. https://doi.org/10.3233/JAD-2011-110977.

Publisher's Note Springer Nature remains neutral with regard to jurisdictional claims in published maps and institutional affiliations. 